\title{
PEMILIHAN KOMPONEN JARINGAN DISTRIBUSI AIR BERSIH DENGAN METODE REKAYASA NILAI PADA PERUMAHAN SAWOJAJAR
}

\author{
Dyah Retno $\mathbf{P}^{1}$
}

\section{ABSTRACT}

PDAM is service company in supplying used water to people's hoeses. But demand of pipe increase dramatically while the number of people population increase sharply and inefficient networking of pipe distribution cause PDAM set up and down the pipe that need high cost

Value engineering is one problem solving to overcome this case with conditions that have recomended. Steps of applied value engineering that can solve integrated contains 5 steps : information step, creative step, analysis step, developing step, and presentation step. Based on analysis result using value engineering study got a comparison between initial alternative design and advised alternative design. Appearance some alternatives here from nerwork of pipe networking function structure produce 729 alternatives from 3 elements : priemer pipe distribution, secondary pipe network, and tersiery pipe network. Thus, analysis result of component alternatives of water pipe distribution is :
- Advised alternative
- Beginning alternative

$$
\text { Performance }=85,541 \text {, }
$$$$
\text { Value }=1,26
$$$$
\text { Performance }
$$$$
=79,149 \text {, }
$$$$
\text { Value }=1,00
$$

\section{Key Words : Value Engineering, Performance, Pipe distribution of water}

\section{PENDAHULUAN}

Perkembangan jumlah penduduk di beberapa kota besar di Indonesia, seperti halnya di Kotamadya Malang, yang merupakan salah satu pusat pemerintahan, pendidikan, industri dan perdagangan bagi propinsi Jawa Timur, menjadi penyebab semakin bertambah dan meningkatnya daerah perumahan atau pemukiman penduduk baru dikota ini. Dengan perkembangan ini, menuntut pemerintah melakukan pengadaan beberapa sarana pendukung untuk melayani kebutuhan masyarakat. Adapun salah satunya adalah sarana instalasi pipa distribusi yang digunakan untuk melayani dan mendistribusikan air bersih di daerah perumahan penduduk.
Sebagaimana halnya dengan PDAM-PDAM lainnya di Indonesia, program pengendalian kehilangan air di PDAM Kotamadya Malang belum berjalan dengan baik. Karena itu, tingkat kehilangan air ( unaccounted-for water ), yang dihitung berdasarkan persentasa volume air yang direkeningkan terhadap produksi, relatif cukup tinggi, yaitu $\pm 41.9 \%$.

Hal tersebut juga terjadi pada Perumahan Sawojajar Malang yang merupakan salah satu perumahan yang berkembang pesat di daerah Malang, terbukti dengan diadakannya perluasan perumahan yaitu Perumahan Sawojajar II. Sarana yang ada di dalam perumahan ini sudah lengkap, mulai dari sekolahan, klinik, pasar, supermarket dan lain sebagainya, dịmana kesemua sarana tersebut 
membutuhkan fasilitas air hersih vano erat

memanfaatkan rekavasa nilai dslom bid-maksines

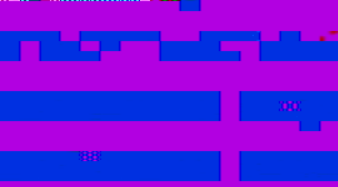

믐묘 驾

\section{$\left[\begin{array}{ll|l}1 & 1\end{array}\right.$}

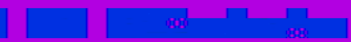

$\min 17$ ए门

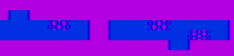

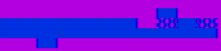
1.1 $11+1$

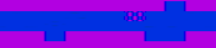
(1) 마미

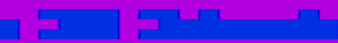

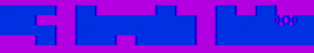

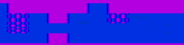
एم 回星田

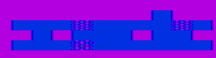

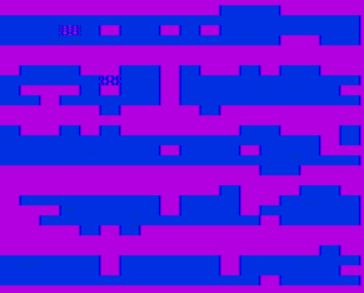
므면

\section{1.}
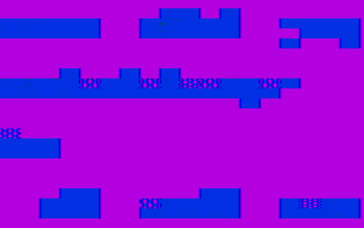

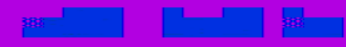
原 듬ำ

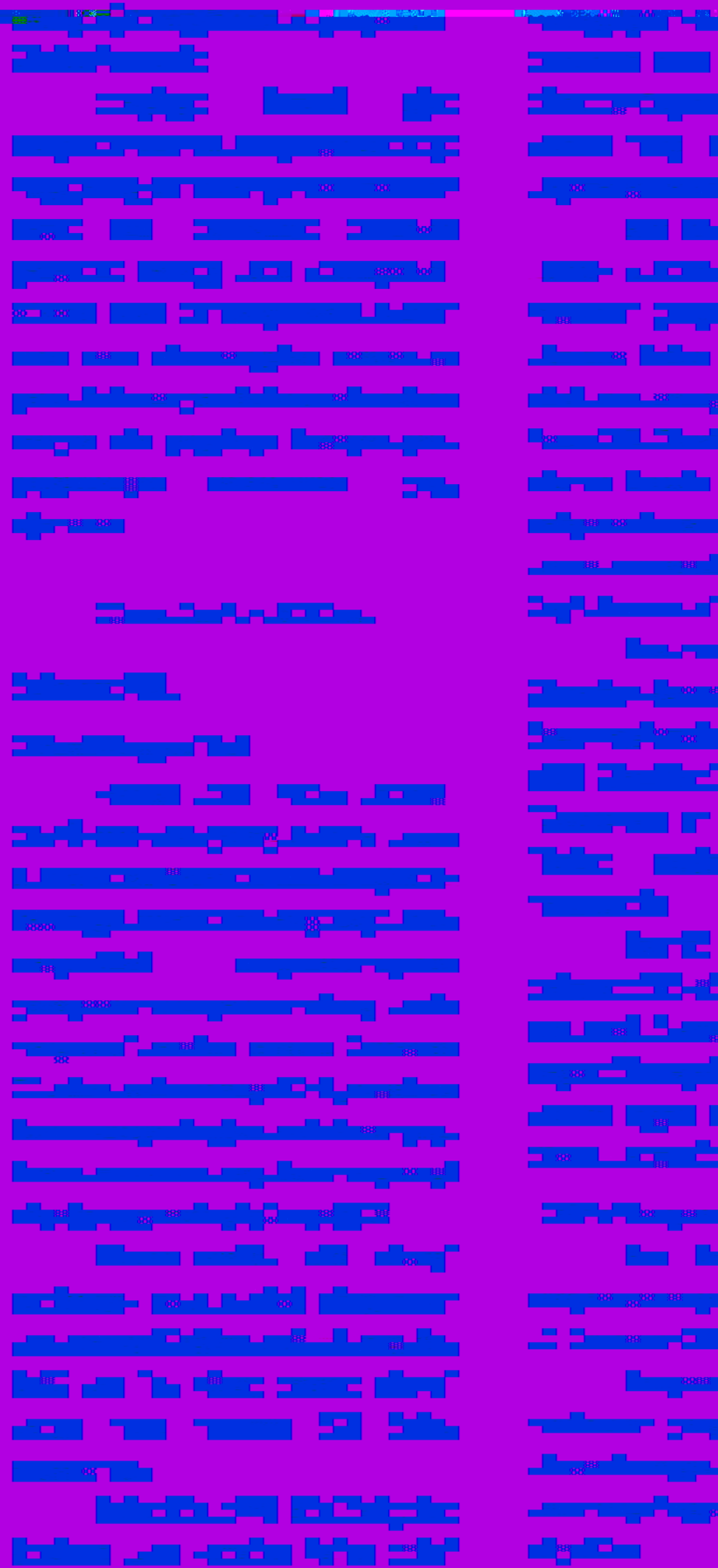




\section{Zimmerman dan Hart}

Rekayasa nilai adalah suatu teknik dan manajemen yang menggunakan pendekatan sistematis untuk mencapai keseimbangan fungsional terbaik antara biaya, keandalan dan penampilan dari suatu sistem atau produk.

\section{Society of American Value Engineering}

Rekayasa nilai adalah suatu teknik yang diterapkan secara sistematis untuk menentukan fungsi suatu produk atau jasa, menentukan nilai moneter dari fungsi tersebut serta memenuhinya dengan biaya total minimum.

\section{Prinsip-Prinsip Rekayasa Nilai}

Pada dasarnya suatu produk dirancang dengan tujuan utama untuk memenuhi kebutuhan dan memberi kepuasan kepada konsumen pemakai produk tersebut. Atribut yang terdapat pada produk yang dipergunakan memenuhi kebutuhan dan memuaskan konsumen pemakainya dinamakan fungsi (value). Sering terjadi bahwa para perancang produk menciptakan fungsi-fungsi pada produk secara berlebihan. Sehingga adanya fungsi-fungsi yang tidak / kurang dibutuhkan ini berakibat timbulnya biaya tambahan yang tidak dikehendaki (unnecessary cost).

Rekayasa nilai mempunyai tujuan untuk mendapatkan nilai (value) semaksimal mungkin. Sedangkan value dapat dinyatakan dengan memperbandingkan performansi dengan biaya sebagai berikut :

$$
\text { VALUE }=\frac{\text { PERFORMANSI }}{B I A Y A}
$$

Dari persamaan di atas, ditunjukkan

parameter keberhasilan sebuah desain, yaitu bahwa nilai dinyatakan sebagai

perbandingan antara performansi yang

diberikan oleh sistem yang sedang didesain dengan jumlah biaya yang dikeluarkan untuk memunculkan fungsi-fungsi yang diberikan oleh sistem. Produk dianggap baik apabila memiliki kesesuaian antara performansi yang diberikan dengan biaya yang dikeluarkan. Sebaliknya produk dianggap tidak baik apabila tidak ada kesesuaian antara performansi yang diberikan dengan biaya yang dikeluarkan.

\section{TAHAPAN DALAM REKAYASA NILAI}

1. Tahap Informasi (Information Phase)

2. Tahap Kreatif (Creative Phase)

3. Tahap Analisa (Judgement Phase)

4. Tahap Pengembangan (Development Phase)

5. Tahap Rekomendasi (Recommendation Phase)

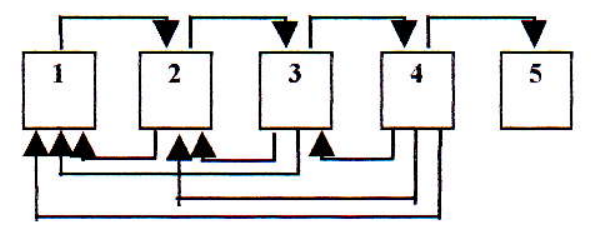

Gambar 1

Hubungan antar fase dalam Rencana Kerja Lima Tahap Rekayasa Nilai

\section{METODOLOGI PENELITIAN}

\section{Data yang Diperlukan}

1. Data Primer

* Kriteria Biaya Pelaksanaan

Kriteria Kekuatan 
* Kriteria Kemudahan Pelaksanaan

* Kriteria Waktu Pemasangan

Kriteria Kemungkinan Pelaksanaan

2. Data sekender

\section{Tahap Pengolahan Data}

\section{Tahap informasi}

- Pengumpulan Data

* Analisa Fungsi ( Diagram FAST )

2. Tahap Kreatif

Memunculkan alternatif

- Mengembangkan alternatif

- Membuat alternatif

\section{Tahap Analisa}

Menganalisa Alternatif

- Analisa keuntungan-kerugian

- Analisa matrik kelayakan

- Analisa matrik evaluasi

- Analisa pembobotan

- Perhitungan performansi

\section{Tahap Pengembangan}

Mengevaluasi Alternatif terpilih

- Analisa biaya alternatif

- Menghitung value

- Memilih alternatif terbaik

\section{Tahap presentasi}

- Mempresentasikan

alternatif

terpilih

- Presentasi alternatif nilai tertinggi

\section{HASIL DAN PEMBAHASAN}

Perencanaan jaringan pipa distribusi air bersih merupakan suatu proses untuk melakukan transportasi kebutuhan pipa menjadi desain alternatif pipa dalam rangka untuk memenuhi kebutuhan sesuai dengan keinginan konsumen. Kebutuhan ini dijabarkan sebagai fungsi utama yang selanjutnya diuraikan menjadi beberapa fungsi operasional.

Masing-masing fungsi dapat menampilkan performansi untuk memenuhi fungsi yang menjadi fungsi utama. Kemudian fungsi itu diterjemahkan menjadi komponen-komponen sebagai pelaksana fungsi. Selanjutnya komponen-komponen tersebut dirangkai dalam bentuk desain struktur jaringan pipa distribusi air bersih.

Adapun yang menjadi fungsi operasional dari struktur jaringan pipa distribusi air bersih adalah sebagai berikut :

\section{* Fungsi 11 PVC \\ Fungsi $12 \mathrm{GP}$ \\ * Fungsi 13 DCIP \\ * Fungsi 21 PVC \\ * Fungsi $22 \mathrm{GP}$ \\ * Fungsi 23 DCIP \\ * Fungsi 31 PVC \\ * Fungsi $32 \mathrm{GP}$ \\ * Fungsi 33 DCIP}

Fungsi-fungsi di atas akan dipenuhi oleh elemen-elemen yang bersesuaian antara lain:

\section{Fungsi Elemen Yang Bersesuaian}

$01 \quad$ Pipa Distribusi

11,12,13 Jaringan Pipa Primer

21,22,23 Jaringan Pipa Sekunder

31,32,33 Jaringan Pipa Tersier

\section{Analisa Kelayakan}

Bagian berikutnya pada tahap ini adalah membuat matrik kelayakan, dengan mempertimbangkan kriteria-kriteria kelayakan di atas. 
Kriteria penilaian dari perencanaan jaringan pipa distribusi air bersih di perumahan Sawojajar Malang adalah sebagai berikut :

\section{Kriteria Biaya Pelaksanaan}

Kriteria untuk menilai biaya yang dikeluarkan dalam mewujudkan kombinasi alternatif.

\section{Kriteria Kekuatan}

Kriteria untuk menilai kemampuan menahan tekanan saat digunakan dari kombinasi alternatif yang diusulkan dengan kombinasi alternatif awal.

\section{Kriteria Kemudahan Pelaksanaan}

Kriteria untuk menilai kemudahan saat pemasangan / penyambungan dari kombinasi alternatif. Apabila semakin sulit pelaksanaannya, maka diberi nilai mendekati 0 . Tetapi apabila semakin mudah pelaksanaannya, maka diberi nilai mendekati 10 .

\section{Kriteria Waktu Pemasangan}

Kriteria untuk menilai waktu yang dibutuhkan saat pemasangan pipa dari kombinasi alternatif.

\section{Kriteria Kemungkinan Pelaksanaan}

Kriteria untuk menilai kemungkinan melaksanakan kombinasi alternatif yang digunakan. Apabila alternatif memiliki kemungkinan pelaksanaan cukup kecil

Akhirnya dari hasil analisa yang berdasarkan matrik kelayakan dari para ahli / pakar tersebut, selanjutnya dibuat dalam bentuk rangking untuk menentukan dari urutan masing-masing alternatif yang dipilih. Rangking teratas adalah penilaian yang terbaik dan diteruskan untuk rangking berikutnya.

Tabel 1

Rangking Penilaian Matrik Kelayakan

\begin{tabular}{|c|c|c|c|c|}
\hline No & JARINGAN PIPA & BAHAN & MERK & TOTAL \\
\hline $\mathbf{1 .}$ & TERSIER & PVC & MASPION & 419 \\
\hline $\mathbf{2 .}$ & TERSIER & PVC & WAVIN & 318 \\
\hline $\mathbf{3 .}$ & TERSIER & PVC & MILYARD & 189 \\
\hline $\mathbf{4 .}$ & TERSIER & GP & MASPION & 382 \\
\hline $\mathbf{5 .}$ & TERSIER & GP & WAVIN & 298 \\
\hline $\mathbf{6 .}$ & TERSIER & GP & MILYARD & 162 \\
\hline $\mathbf{7 .}$ & TERSIER & DCIP & MASPION & 315 \\
\hline $\mathbf{8 .}$ & TERSIER & DCIP & WAVIN & 231 \\
\hline $\mathbf{9 .}$ & TERSIER & DCIP & MILYARD & 146 \\
\hline $\mathbf{1 0 .}$ & SEKUNDER & PVC & MASPION & 422 \\
\hline $\mathbf{1 1 .}$ & SEKUNDER & PVC & WAVIN & 304 \\
\hline $\mathbf{1 2 .}$ & SEKUNDER & PVC & MILYARD & 186 \\
\hline $\mathbf{1 3 .}$ & SEKUNDER & GP & MASPION & 354 \\
\hline $\mathbf{1 4 .}$ & SEKUNDER & GP & WAVIN & 256 \\
\hline $\mathbf{1 5 .}$ & SEKUNDER & GP & MILYARD & 175 \\
\hline $\mathbf{1 6 .}$ & SEKUNDER & DCIP & MASPION & 283 \\
\hline $\mathbf{1 7 .}$ & SEKUNDER & DCIP & WAVIN & 229 \\
\hline $\mathbf{1 8 .}$ & SEKUNDER & DCIP & MILYARD & 145 \\
\hline $\mathbf{1 9 .}$ & PRIMER & PVC & MASPION & 429 \\
\hline
\end{tabular}




\begin{tabular}{|c|c|c|c|c|}
\hline $\mathbf{2 0 .}$ & PRIMER & PVC & WAVIN & 292 \\
\hline $\mathbf{2 1 .}$ & PRIMER & PVC & MILYARD & 186 \\
\hline $\mathbf{2 2 .}$ & PRIMER & GP & MASPION & 326 \\
\hline $\mathbf{2 3 .}$ & PRIMER & GP & WAVIN & 229 \\
\hline $\mathbf{2 4 .}$ & PRIMER & GP & MILYARD & 171 \\
\hline $\mathbf{2 5 .}$ & PRIMER & DCIP & MASPION & 313 \\
\hline $\mathbf{2 6 .}$ & PRIMER & DCIP & WAVIN & 249 \\
\hline $\mathbf{2 7 .}$ & PRIMER & DCIP & MILYARD & 160 \\
\hline
\end{tabular}

\section{Matrik Evaluasi}

Kriteria yang digunakan untuk matrik evalusi ada 7 macam yaitu Kekuatan, Stabilitas, Biaya Pelaksanaan, Umur Pakai, Kemungkinan Pelaksanaan, Waktu Pemasangan dan Kemudahan Pelaksanaan. Matrik evaluasi ini juga dilakukan dengan menyebarkan kuisioner terhadap para responden / para ahli yang mampu dalam merencanakan suatu struktur jaringan pipa distribusi air bersih di daerah perumahan.

Skala penilaian terhadap masing-masing kriteria adalah sebagai berikut :

- Nilai 1 dan $2=$ Tidak Baik

- Niai 3 dan $4=$ Kurang Baik

- Nilai 5 dan $6=$ Cukup Baik

- Nilai 7 dan $8=$ Baik

- Nilai 9 dan $10 \quad=$ Sangat Baik

Tabel 2

Rangking Matrik Evaluasi

\begin{tabular}{|c|c|c|c|c|c|c|c|c|c|c|c|c|c|}
\hline \multirow{2}{*}{ NO } & \multirow{2}{*}{$\begin{array}{c}\text { Alternatif } \\
\text { Desain }\end{array}$} & \multirow{2}{*}{$\begin{array}{c}\text { Jaringan } \\
\text { Pipa }\end{array}$} & \multirow{2}{*}{$\begin{array}{c}\text { Diameter } \\
\text { Pipa }\end{array}$} & \multirow{2}{*}{$\begin{array}{c}\text { Bahan } \\
\text { Pipa }\end{array}$} & \multirow{2}{*}{$\begin{array}{c}\text { Merk } \\
\text { Pipa }\end{array}$} & \multicolumn{7}{|c|}{ Nilai Tiap Kriteria } & \multirow{2}{*}{ Total } \\
\hline & & & & & & 1 & 2 & 3 & 4 & 5 & 6 & 7 & \\
\hline \multirow[t]{3}{*}{1} & \multirow[t]{3}{*}{ Awal } & Primer & 6 & PVC & Maspion & & & & & & & & \\
\hline & & Skunder & 4 & PVC & Maspion & 79 & 82 & 81 & 80 & 81 & 84 & 78 & 565 \\
\hline & & Tersier & 3 & PVC & Maspion & & & & & & & & \\
\hline \multirow[t]{3}{*}{2} & \multirow[t]{3}{*}{1} & Primer & 6 & PVC & Maspion & & & & & & & & \\
\hline & & Skunder & 4 & PVC & Maspion & 82 & 84 & 88 & 89 & 86 & 87 & 86 & 602 \\
\hline & & Tersier & 3 & GP & Maspion & & & & & & & & \\
\hline \multirow[t]{3}{*}{3} & \multirow[t]{3}{*}{2} & Primer & 6 & PVC & Maspion & & & & & & & & \\
\hline & & Skunder & 4 & GP & Maspion & 70 & 73 & 78 & 73 & 71 & 68 & 67 & 500 \\
\hline & & Tersier & 3 & PVC & Maspion & & & & & & & & \\
\hline \multirow[t]{3}{*}{4} & \multirow[t]{3}{*}{3} & Primer & 6 & PVC & Wavin & & & & & & & & \\
\hline & & Skunder & 4 & PVC & Maspion & 89 & 88 & 87 & 86 & 90 & 84 & 93 & 617 \\
\hline & & Tersier & 3 & PVC & Maspion & & & & & & & & \\
\hline \multirow[t]{3}{*}{5} & \multirow[t]{3}{*}{4} & Primer & 6 & GP & Maspion & & & & & & & & \\
\hline & & Skunder & 4 & PVC & Maspion & 70 & 72 & 75 & 76 & 73 & 71 & 70 & 507 \\
\hline & & Tersier & 3 & PVC & Maspion & & & & & & & & \\
\hline \multirow[t]{3}{*}{6} & \multirow[t]{3}{*}{5} & Primer & 6 & DCIP & Maspion & & & & & & & & \\
\hline & & Skunder & 4 & PVC & Maspion & 69 & 72 & 68 & 73 & 70 & 71 & 68 & 491 \\
\hline & & Tersier & 3 & PVC & Maspion & & & & & & & & \\
\hline \multirow[t]{3}{*}{7} & \multirow[t]{3}{*}{6} & Primer & 6 & PVC & Maspion & & & & & & & & \\
\hline & & Skunder & 4 & GP & Maspion & 80 & 78 & 79 & 82 & 80 & 77 & 78 & 554 \\
\hline & & Tersier & 3 & GP & Maspion & & & & & & & & \\
\hline
\end{tabular}


Hasil akhir analisa yang didasarkan pada penyaringan yang dilakukan dengan menggunakan matrik evaluasi, kemudian dijadikan acuan dalam perhitungan performansi lebih lanjut.
Performansi dari masing-masing alternatif dapat ditabelkan dengan cara mengalikan total bobot kriteria dengan nilai kriteria dari matrik evaluasi dan selanjutnya dijumlahkan sebagai berikut :

Tabel 3

Perhitungan Performansi Alternatif

\begin{tabular}{|c|c|c|c|c|c|c|c|c|c|}
\hline \multirow{4}{*}{ Alternatif } & \multicolumn{7}{|c|}{ Kriteria } & \multirow{2}{*}{ Pn } & \multirow{2}{*}{ Rangking } \\
\hline & 1 & 2 & 3 & 4 & 5 & 6 & 7 & & \\
\hline & \multicolumn{7}{|c|}{ Bobot Tiap Kriteria } & & \\
\hline & 0.342 & 0.249 & $\begin{array}{c}0.015 \\
9\end{array}$ & 0.097 & 0.058 & 0.038 & 0.028 & & \\
\hline Awal & 79 & 82 & 81 & 80 & 81 & 84 & 78 & 78.149 & 3 \\
\hline 1 & 82 & 84 & 88 & 89 & 86 & 87 & 86 & 82.287 & 2 \\
\hline 2 & 70 & 73 & 78 & 73 & 71 & 68 & 67 & 70.178 & 5 \\
\hline 3 & 89 & 88 & 87 & 86 & 90 & 84 & 93 & 85.541 & 1 \\
\hline 4 & 70 & 72 & 75 & 76 & 73 & 71 & 70 & 70.057 & 6 \\
\hline 5 & 69 & 72 & 68 & 73 & 70 & 71 & 68 & 68.081 & 7 \\
\hline 6 & 80 & 78 & 79 & 82 & 80 & 77 & 78 & 77.047 & 4 \\
\hline
\end{tabular}

\section{PENENTUAN NILAI (VALUE)}

Pemilihan alternatif yang terbaik harus dapat dilihat berdasarkan nilai yang diberikan dari masing-masing alternatif desain.

$$
\mathrm{V}=\frac{P}{C}
$$

$$
\begin{aligned}
\text { Dimana : } \mathbf{P} & =\text { Performansi } \\
\mathrm{C} & =\text { Cost } / \text { Biaya } \\
\mathrm{V} & =\text { Nilai }
\end{aligned}
$$

Karena P merupakan angka besaran (satuan skala 0 , maka perlu dikonversikan terhadap satuan biaya agar perbandingan yang dilakukan dapat menghasilkan nilai ( value )

$$
\mathrm{V}=\frac{P}{C}=\frac{P^{\prime}}{C^{\prime}}=\frac{P^{\prime \prime}}{C^{\prime \prime}}
$$

Dimana :

- $\quad \mathrm{P}=$ Performansi

- $\quad \mathrm{C}=$ Biaya awal

- $\quad \mathrm{P}^{\prime}=$ Performansi pada rancangan sebenarnya (alternatif)

- $\quad C^{\prime}=$ Biaya pada kondisi rancangan sebenarnnya (alternatif)

- $\mathrm{P} "=$ Performansi pada kondisi rancangan seharusnya

- $\quad \mathrm{C}^{\prime \prime}=$ Biaya pada kondisi rancangan seharusnya

Maka : 
Nilai dari masing-masing alternatif dapat dilihat pada tabel dibawah ini :

Tabel 4

Nilai Desain Jaringan Pipa Distribusi Air Bersih

\begin{tabular}{|l|l|c|c|}
\hline NO & ALTERNATIF & NILAI & RANGKING \\
\hline 1 & Awal & 1.000 & 4 \\
\hline 2 & Alternatif 1 & 1.129 & 2 \\
\hline 3 & Alternatif 2 & 0.918 & 5 \\
\hline 4 & Alternatif 3 & 1.26 & 1 \\
\hline 5 & Alternatif 4 & 0.914 & 6 \\
\hline 6 & Alternatif 5 & 0.68 & 7 \\
\hline 7 & Alternatif 6 & 01.038 & 3 \\
\hline
\end{tabular}

Secara analisa maka yang mempunyai nilai terbesar adalah alternatif 3 dengan $\mathrm{V}=1,26$ dan alternatif 1 dengan $\mathrm{V}=1.129$.

Dengan mengetahui secara jelas dari hasil analisa, akan memberikan ketetapan bahwa alternatif desain 3 dapat dikembangkan lebih lanjut. Kemudian alterntif 1 juga dapat dikembangkan apabila alternatif desain 3 tidak dapat direalisasikan.

Spesifikasi teknis yang dimiliki oleh alternatif desain 3 dan alternatif desain 1 yang mungkin akan dikembangkan adalah sebagai berikut :

\section{Alternatif 3 :}

- Jaringan Pipa Primer : PVC Maspion

- Jaringan Pipa Skunder : PVC Maspion

- Jaringan Pipa Tersier : PVC Wavin

- Biaya

Rp.314.087.238,7

2 Alternatif 1 :

- Jaringan Pipa Primer

PVC
- Jaringan Pipa Skunder : PVC Maspion

- Jaringan Pipa Tersier Maspion

- Biaya

Rp.334.483.637,2

\section{KESIMPULAN}

Setelah dilakukan pemunculan alternatifalternatif pipa distribusi air bersih, maka dapat disumpulkan bahwa yang terpilih sebagai alternatif dengan performansi yang baik dan biaya yang lebih rendah adalah alternatif ke-3 dengan spesifikasi sebagai berikut : Jaringan Pipa Primer PVC Maspion, Jaringan Pipa Skunder PVC Maspion dan Jaringan Pipa Tersier PVC Wavin .

Alternatif desain tersebut merupakan alternatif instalasi pipa distribusi air bersih yang memiliki performansi yang lebih baik dari desain awal yaitu 85.54 , biaya yang lebih rendah dari desain awal yaitu 314087238.7 dan value yang lebih baik 
dari desain awal yaitu 1.25, dengan keuntungan sebagai berikut :

- Kekuatannya relatif baik

- Harganya relatif murah

- Permukaan pipa licin

- Tahan terhadap korosi

- Mudah pengerjaannya

\section{DAFTAR PUSTAKA}

Sudjana, 1992, Metode Statistika, Edisi 5, Tarsita, Bandung.

Zimmerman I.W. and Hurt, G.D, 1982, Value Engineering, Practical Approach For Owner, Designer and
Contractor, Van Hoshand Reinhold

Company, New York.

Corporate Pland PDAM Kotamadya Malang, $\mathbf{2 0 0 0}$

Bambang Permadi S,SE, 1992, $\boldsymbol{A H} \boldsymbol{P}$, PAUEK-UI, Jakarta,

Ronald E. Walpole, Raymond H Myers, Ilmu Peluang dan Statistika Untuk Insinyur dan Ilmuwan, Edisi ke 4, ITB , Bandung

Thomas 1. Saaty, 1993, Proses Hirarki Analitik Untuk Pengambilan Keputusan Dalam Study Yang Komplek, PT. Pustaka Biraman Pressindo 